\title{
СПИСАНИЕ НЕУСТОЙКИ ПО ГОСУДАРСТВЕННЫМ (МУНИЦИПАЛЬНЫМ) КОНТРАКТАМ КАК СЛУЧАЙ ОСВОБОЖДЕНИЯ ОТ ГРАЖДАНСКО-ПРАВОВОЙ ОТВЕТСТВЕННОСТИ
}

\begin{abstract}
Аннотация: Предметом исследования являются проблемы списания начисленных сумм неустоек (итрафов, пеней) исполнителям за неисполнение государственного контракта. Авторы подробно рассматривают основания и условия списания неустоек по государственным контрактам, анализируют судебную практику. В статье исследуется вопросы: является ли списание неустойки правом или обязанностью заказчика, о возможности применения правил о списании неустойки к Закону № 94-Ф3, о правомерности исключения из установленного правила освобождения от ответственности случая, когда неустойка перечисляется в бюджет. В ходе исследования были использованы как общенаучные, так и частно-научные методы научного познания: диалектический, формально логический, формально-юридчческий, сравнительно-правовой. На основе анализа действующего законодательства и правоприменительной практики сделан вывод, что списание начисленных сумм неустоек (штрафов, пеней) - это не право заказчика, а его обязанность. Возможность осуществлять списание заказчиком уже начисленных сумм неустоек (штрафов, пеней) является одним из оснований освобождения поставщика (подрядчика, исполнителя) от гражданско-правовой ответственности.

Ключевые слова: Неустойка, основания освобождения, государственный контракт, муниципальный контракт, гражданская ответственность, списание неустойки, государственный заказчик, задолженность, бюджет, антикризисные меры.

Abstract: The object of this research is the problems of write-offs of penalties (fines, fees) for failure to fulfill a state contract. The authors examine the grounds and conditions for cancellation of penalties in government contracts and analyze judicial practice. The article examines the questions: is the write-off of penalty a right or obligation of the purchaser; about the possibility of the application of the rules on the write-off of penalty to the Law № 94-FZ, on the legality of exceptions to the established rule of exemption from liability if the penalty is transferred to the budget. The work was based on the general scientific and private scientific methods of cognition: dialectical, formal logical, formal legal, comparative-legal. Based on the analysis of the current legislation and law enforcement practices, the authors conclude that the cancellation of accrual of penalties (fines, fees) is not a right of the purchaser, but their responsibility. The ability to carry out the cancellation by the purchaser of amounts of already incurred penalties (fines, fees) is one of the reasons the release of supplier (contractor) from civil liability.
\end{abstract}

Keywords: Budget, debt, state customer, write-off, civil liability, municipal contract, government contract, exemption, penalty, anti-crisis measures.

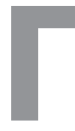

ражданско-правовая ответственность, являясь одним из видов юридической ответственности, предусматривает применение к правонарушителю установленных законом или договором мер воздействия, влекущих для него отрицательные, экономически невыгодные последствия имущественного характера. При этом в сфере государственных закупок включение в контракт условия об ответственности поставщика (подрядчика, исполнителя) за неисполнение или ненадлежащее исполнение обязательств, предусмотренных контрактом, является обязательным (статья 34 Федерального закона от 05.04.2013 № 44-Ф3 «О контрактной системе в сфере закупок товаров, работ, услуг для обеспечения государственных и муниципальных нужд» (далее - Закон № 44-Ф3). Такая ответственность выражается в уплате неустойки (штрафа, пени). Причем взимание штрафа осуществляется при неисполнении или ненадлежащем исполнении обязательств по контракту, а пени - в случае просрочки исполнения контрагентом обязательств (в том числе гарантийного обязательства) по контракту (ч. 5, 7, 8 ст. 34 Закона № 44-Ф3).

Однако при применении любого вида юридической ответственности подлежат выяснению основания, освобождающие от ответственности. Отметим, что законодательство не содержит определение понятия «освобождение от гражданско-правовой ответственности». Научные работы в гражданском праве, посвященные освобождению от ответственности, немногочисленны. При этом одним из наиболее полных определений понятия «освобождение от гражданско-правовой ответственности», на наш взгляд, 


\section{Право и политика $11(203) \cdot 2016$}

является определение, данное Д. В. Богдановым: «Освобождение от гражданско-правовой ответственности - это безусловное и окончательное избавление от обязанности претерпевать меры ответственности за совершенное, имеющее все элементы состава, гражданское правонарушение в связи с нецелесообразностью привлечения к ответственности по основаниям, предусмотренным законом» [2, с. 79].

Следует также упомянуть И. Н. Тихоненко, отмечающего, что в институте освобождения от юридической ответственности реализуются принципы справедливости, гуманизма, индивидуализации юридической ответственности [5, с. 34]. Как можно заметить, как правило, законодатель указывает на обстоятельства, наличие которых освобождает от ответственности одну из сторон гражданского правоотношения.

В частности, сторона контракта освобождается от уплаты неустойки (штрафа, пени), если докажет, что обязательство, предусмотренное контрактом, не исполнено или исполнено ненадлежащим образом вследствие действия обстоятельств непреодолимой силы или по вине другой стороны (ч. 9 ст. 34 Закона № 44-Ф3). Данная норма соответствует общим правилам освобождения от ответственности, указанным в статье 401 Гражданского кодекса Российской Федерации.

Как правило, обстоятельства, освобождающие от ответственности, свидетельствуют о том, что правонарушение или правонарушитель утратили или не имели степени общественной опасности, необходимой для привлечения к ответственности, и поэтому нецелесообразно привлечение к ответственности. Причем основания освобождения от ответственности являются безусловными и окончательными.

Обратим внимание на еще один случай освобождения от ответственности, связанный с изменением в 2015 году ключевых исходных условий и факторов развития экономики России и установленный в целях обеспечения исполнения государственных контрактов, снижения финансовой нагрузки на участников закупок, а именно - списание начисленных сумм неустоек (штрафов, пеней) исполнителям за неисполнение государственного контракта.

Так, Федеральным законом от 31.12.2014 № 498-Ф3 (пункт 4 статья 1) были введены нормы, действующие на период до 01.01.2016, в отношении возможности заказчика осуществлять списание начисленных сумм неустоек (штрафов, пеней) в 2015 году в случаях и в порядке, которые определены Правительством РФ (пункт 6.1).

Следует отметить, что Закон № 44-ФЗ предусматривает списание при условии завершения испол- нения поставщиком (подрядчиком, исполнителем) в 2015 году в полном объеме всех обязательств, предусмотренных контрактом, кроме гарантийных.

Понятно, что предоставление государственным заказчикам списания неустоек (штрафов, пеней) является одной из антикризисных мер, призванной поддержать стабильное функционирование системы государственных закупок. Вместе с тем, следует учитывать и то, что списание допускается по контрактам, обязательства по которым исполнены в полном объеме (кроме тех, условия которых изменены в 2015 году по основаниям, предусмотренным законом). Таким образом, указанное свидетельствует об утрате общественной опасности совершенного правонарушения, что является основанием для освобождения от гражданско-правовой ответственности.

Кроме того, с учетом лексикологического анализа термина «освобождение от ответственности», по мнению О. А. Кузнецовой, необходимо сначала иметь нормативную возможность к ответственности привлечь, а потом уже от нее освободить [3, с. 100]. Заметим, что в данном случае списание начисленных сумм распространяется на принятую к учёту задолженность поставщика (подрядчика, исполнителя).

Случаи и порядок осуществления заказчиком в 2015 году списания начисленных сумм неустоек (штрафов, пеней) регламентированы Постановлением Правительства РФ от 05.03.2015 № 196, в пункте 5 которого указано, что списание начисленных сумм неустоек (штрафов, пеней) осуществляется путем списания с учета задолженности поставщиков по денежным обязательствам перед заказчиком в порядке, установленном соответствующим финансовым органом.

Постановление Правительства РФ от 14.03.2016 № 190 «О случаях и порядке предоставления заказчиком в 2016 году отсрочки уплаты неустоек (штрафов, пеней) и (или) осуществления списания начисленных сумм неустоек (штрафов, пеней)» (далееПостановление № 190) определило, в каких случаях и в каком порядке заказчики списывают задолженность по контрактамв 2016 году. В соответствии с пунктом 1 данного Постановления заказчики осуществляют списание начисленных сумм неустоек (штрафов, пеней) при завершении в полном объеме в 2015 и 2016 гг. исполнения контрагентом всех обязательств, предусмотренных контрактом, за исключением гарантийных обязательств. Списание в 2016 году начисленных по контрактам сумм неустоек (штрафов, пеней) осуществляется заказчиком в Порядке, аналогичном действовавшему в 2015 году. Так, согласно Порядку № 44н списанию подлежит неуплаченная задолженность по 
DOI: 10.7256/1811-9018.2016.11.20823

При цитировании этой статьи сноска на doi обязательна

Юридический практикум

неустойкам, которая не должна превышать 5\% цены контракта или может превышать 5\% цены контракта, но составлять не более $20 \%$ цены контракта при условии уплаты контрагентом 50\% задолженности до окончания 2016 года.

Для принятия решения о списании неустойки необходимо провести сверку с исполнителем о наличии задолженности. При этом неподтвержденная задолженность не подлежит списанию. Далее для списания неустойки необходимо получить документы, подтверждающие исполнение контрагентом обязательств (за исключением гарантийных обязательств) по контракту в полном объеме, если сумма неустойки превысила предел 5\%, то дополнительно запросить информацию о зачислении денежных средств в бюджет или на счет заказчика. Решение о списании задолженности принимается комиссией заказчика по поступлению и выбытию активов и оформляется внутренним документом (приказом, распоряжением), содержащим информацию о неуплаченной задолженности, включенную в реестр контрактов, и обязательные реквизиты первичных учетных документов, предусмотренные пункт 7 Инструкции № 157н.

Не позднее 20 рабочих дней со дня наступления соответствующего основания заказчик направляет контрагенту уведомление о списании начисленной и неуплаченной задолженности с указанием ее размера по форме согласно Приложению к Порядку № 44н. Заказчик, не наделенный полномочиями администратора доходов бюджета, должен не позднее трех рабочих дней после списания неустойки направить администратору доходов бюджета информацию о произведенном списании с указанием суммы задолженности и кода классификации доходов бюджетов.

Таким образом, порядок действий заказчика определен и поставлен в зависимость от суммы неустойки, которая должна быть подтверждена.

Несмотря на подробное нормативное закрепление оснований и порядка списания неустойки, в судебной практике возник ряд вопросов, связанных с применением части 6.1 статьи 34 Закона № 44-ФЗ и постановлений Правительства № 190, 196.

В частности, спорно положение о том, является ли списание задолженности по неустойкам правом или обязанностью заказчика. Судебная практика свидетельствует о неоднозначности позиций судов. В одних случаях, суды исходят из того, что списание неустойки является обязанностью заказчика, а не его правом. Такой вывод обосновывается тем, что выполнение постановлений Правительства РФ № 190 и № 196 является реализацией, в частности, плана первоочередных мероприятий по обеспечению устойчивого развития экономики и социальной стабильности, а предоставление отсрочки уплаты неустоек и (или) осуществления списания начисленных сумм неустоек является одной из мер поддержки поставщиков (например, постановление Арбитражного суда Западно-Сибирского округа от 22.01.2016 по делу № А46-3302/2015, постановление Арбитражного суда Поволжского округа от 11.03.2016 по делу № А06-4184/2015).

Согласно второй позиции норма о списании неустойки не носит обязательного характера для истца и не препятствует обращению в суде требованием о взыскании неустойки. Кроме того, согласно порядку списания неустойки (Приказ Минфина России от 29.06.2015 № 98н) решение о списании неустойки принимается комиссией по поступлению и выбытию активов заказчика и оформляется внутренним распорядительным документом заказчика. Заказчик в каждом случае самостоятельно принимает решение о возможности списания штрафных санкций, что не является его безусловной обязанностью. Таким образом, невыполненная заказчиком обязанность по списанию денежных средств не может быть возложена на поставщика в судебном порядке (например, постановление Девятого арбитражного апелляционного суда от 30.06.2016 по делу № А40-246991/2015, постановление Шестого арбитражного апелляционного суда от 08.08.2016 по делу № А73-2969/2016).

Представляется, что списание начисленных сумм неустоек (штрафов, пеней) - это не право заказчика, а его обязанность, которая, однако, поставлена в зависимость от перечисленных выше условий. Такой вывод следует из толкования пункта 1 Постановления № 196, в котором указано, что заказчики осуществляют списание неустоек, а не «вправе» совершать такие действия. Начисление заказчиком неустойки без принятия мер по ее принудительному взысканию (в судебном порядке) с последующим ее списанием в наибольшей мере целям части 6.1 статьи 34 Закона № 44-ФЗ. Таким образом, при невыполнении заказчиком данной обязанности и последующем обращении в суд с иском о взыскании начисленной неустойки, суд должен применить соответствующую норму права и рассмотреть наличие условий для освобождения контрагента от ответственности за нарушение условий контракта. В противном случае в зависимости от субъективного усмотрения и поведения (бездействия) различных заказчиков отдельные поставщики (подрядчики) будут поставлены в неравное положение, а нормы Постановлений № 190 и № 196 фактически по усмотрению отдельных заказчиков не будут исполняться. По одному из рассмотренных дел, суд обоснованно указал на то, заказчик должен был не 


\section{Право и политика $11(203) \cdot 2016$}

только направлять претензию с требованием оплатить неустойку, но и направить в адрес исполнителя акт сверки неуплаченной задолженности для принятия решения о возможности списания или рассрочки уплаты неустойки. Несоблюдение заказчиком предусмотренного порядка фактически лишило исполнителя возможности реализовать предусмотренный законом механизм списания неустойки (постановление Пятнадцатого арбитражного апелляционного суда от 14.07.2016 № A53-7084/2016).

Еще одним важным моментом является тот факт, что Постановления № 190 и № 196 приняты в порядке исполнения Закона № 44-Ф3, однако, на наш взгляд, это не исключает их применения к контрактам, заключенным в соответствии с положениями Федерального закона от 21.07.2005 № 94-Ф3 «О размещении заказов на поставки товаров, выполнение работ, оказание услуг для государственных и муниципальных нужд», утратившим силу с 01.01.2014.

Такой вывод основывается на том, что в силу пункта 2 статьи 4 Гражданского кодекса РФ к отношениям, возникшим до введения в действие акта гражданского законодательства, он применяется к правам и обязанностям, возникшим после введения его в действие. Отношения сторон по договору, заключенному до введения в действие акта гражданского законодательства, регулируются в соответствии со статьей 422 ГК РФ.

Согласно статье 112 Закона № 44-Ф3, данный закон применяется к отношениям, связанным с осуществлением закупок товаров, работ, услуг для обеспечения государственных или муниципальных нужд, извещения об осуществлении которых размещены в единой информационной системе или на официальном сайте Российской Федерации в информационно - телекоммуникационной сети «Интернет» для размещения информации о размещении заказов на поставки товаров, выполнение работ, оказание услуг либо приглашения принять участие в которых направлены после дня вступления в силу Закона № 44-Ф3. К отношениям, возникшим до дня вступления в силу Закона № 44-Ф3, он применяется в части прав и обязанностей, которые возникнут после дня его вступления в силу, если иное не предусмотрено статьей 112.

Следовательно, неустойка, начисленная на основании контракта, заключенного по Закону № 94Ф3, подлежит списанию на основании положений Закона № 44-Ф3, поскольку право на списание неустойки возникло у исполнителя после вступления в силу Закона № 44-Ф3.

Еще один вопрос возник в связи с разъяснением в письме Минфина России от 22.07.2015 № 02-02-
04/42194 о том, что если в контракт включено условие о перечислении заказчиком сумм начисленных неустоек в соответствующий бюджет (для государственных (муниципальных) заказчиков) или о зачете неустойки при оплате контракта (для бюджетных, автономных учреждений, ГУП), то списание неустойки не осуществляется. На сегодняшний день практика по данному вопросу складывается неоднозначно.

В одних случаях суды исходят из того, что поскольку в контракт включено условие о перечислении заказчиком сумм начисленных неустоек в соответствующий бюджет, то списание заказчиком неустойки не осуществляется, соответственно, применяются положения указанного письма (например, постановление Седьмого арбитражного апелляционного суда от 10.06.2016 по делу № А45-26263/2015).

Сторонники иного подхода считают, что в таких случаях подлежат применению положения Постановлений № 190 и № 196, и неустойка подлежит списанию, отмечая при этом рекомендательный характер письма Минфина России от 22.07.2015 № 02-02-04/42194.

Кроме того, следует упомянуть и о позиции судов, согласно которой положения письма Минфина России от 22.07.2015 № 02-02-04/42194 при рассмотрении споров о списании неустойки применению не подлежат, поскольку указанное письмо не было официально опубликовано, а в силу пункта 10 Указа Президента Российской Федерации от 23.05.1996 № 763 «О порядке опубликования и вступления в силу актов Президента Российской Федерации, Правительства Российской Федерациии нормативных правовых актов федеральных органов исполнительной власти» нормативные правовые акты федеральных органов исполнительной власти, кроме актов и отдельных их положений, содержащих сведения, составляющие государственную тайну, или сведения конфиденциального характера, не прошедшие государственную регистрацию, а также зарегистрированные, но не опубликованные в установленном порядке, не влекут правовых последствий, как не вступившие в силу, и не могут служить основанием для регулирования соответствующих правоотношений, применения санкций к гражданам, должностным лицам и организациям за невыполнение содержащихся в них предписаний (например, постановление Четвертого арбитражного апелляционного суда от 31.03.2016 по делу № А78-15657/2015).

Полагаем, что письмо Минфина РФ не является нормативно-правовым актом, позиция Минфина РФ имеет информационно-разъяснительный характер по вопросам применения законодательства. Очевидно, что письмом Минфина РФ невозможно предусмотреть 
DOI: $10.7256 / 1811-9018.2016 .11 .20823$

При цитировании этой статьи сноска на doi обязательна

Юридический практикум

возможность или невозможность освобождения от гражданско-правовой ответственности.

Прав А. А. Байкалов, утверждающий, что в данном случае Минфин России фактически «заблокировал» возможность списания неустойки, дарованную антикризисным Постановлением Правительства РФ от 14.03.2016 № 190, и, как следствие, условие контракта о перечислении заказчиком сумм начисленных неустоек в соответствующий бюджет дает право заказчикам не исполнять обязанность по списанию неустойки [1].

Считаем, что таким образом бюджетные, автономные учреждения, государственные унитарные предприятия поставлены в неравное положение по отношению к остальным участникам госконтрактов, так как заказчик может воспользоваться своим правом на удержание и перечисление начисленных неустоек в соответствующий бюджет, отказав поставщику (подрядчику, исполнителю) в списании задолженности по начисленным пени.

Необходимо учитывать, что Постановления № 190 и № 196 были изданы для поддержания поставщиков товаров/услуг в период кризиса. Таким образом, бюджетные и автономные учреждения, государственные унитарные предприятия, осуществляющие закупки в соответствии с Законом № 44-Ф3, лишаются антикризисных льгот.

Следует отметить, что по поводу применения письма Минфина России от 22.06.2015 N 02-0204/42194 в качестве основания для отказа в списании заказчиком сумм начисленных неустоек в письме Минфина России от 24.11.2015 № 02-04-10/68167 были даны разъяснения о том, что письма Минфина России не являются нормативными правовыми актами и носят рекомендательный характер. Вместе с тем поясняется, что к списанию принимается исключительно не уплаченная поставщиком (подрядчиком, исполнителем) задолженность.

Так, при предъявлении исполнителю неустойки государственный (муниципальный) заказчик обязан перечислить ее сумму в доход бюджетов системы Российской Федерации, а исполнителю выплатить сумму, уменьшенную на величину неустойки. Перечисление в установленном порядке неустойки в доход соответствующего бюджета бюджетной системы РФ осуществляется на основании платежного документа, оформленного получателем бюджетных средств, с указанием исполнителя, за которого осуществляется перечисление неустойки (пеней, штрафов) в соответствии с условиями государственного (муниципального) контракта.

В случае, если в контракт включено условие о перечислении заказчиком сумм начисленных неусто- ек в соответствующий бюджет (для государственных (муниципальных) заказчиков) или о зачете неустойки при оплате контракта (для бюджетных, автономных учреждений, государственных унитарных предприятий), то возникшая в таком случае задолженность не признается неуплаченной.

Согласно п. п. 2, 3 ст. 160.1 Бюджетного кодекса Российской Федерации учет начисления и поступления в доход бюджета суммы неустойки (пеней, штрафов) по государственному (муниципальному) контракту на основании вышеуказанных актов приемки осуществляют администраторы доходов в соответствии с правовым актом главного администратора доходов о наделении полномочиями.

Как отмечают В. А. Сергеева, А. С. Маркитантова, подход к правовому регулированию вопроса списания задолженности, которая относится к доходам бюджетов или доходам бюджетных учреждений, созданных публично-правовыми образованиями, обусловлен принципом самостоятельности бюджетов, гарантирующим право и устанавливающим обязанность органов государственной власти и органов местного самоуправления самостоятельно осуществлять бюджетный процесс. Несмотря на то, что решение о списании задолженности оформлено федеральным законом, а основания определены постановлением Правительства РФ, финансовые органы вправе, исходя из сложившейся учетной политики, определить порядок взаимодействия заказчиков и их контрагентов, в том числе условия для списания задолженности и требования к первичным документам, необходимым для ее списания $[4$, с. 66$]$.

Вышеизложенное позволяет говорить о том, что исключение из установленного правила освобождения от ответственности путем списания заказчиком неустоек, в случае если неустойка перечисляется в бюджет, правомерно.

Подводя итог, можно сделать вывод, что одна из антикризисных поправок в Закон № 44-ФЗ, принятая еще в декабре 2014 года, наделила заказчика полномочиями по предоставлению отсрочки уплаты неустоек (штрафов, пеней) и (или) осуществлению списания начисленных сумм неустоек (штрафов, пеней) в случаях и в порядке, определенных Правительством Российской Феденации. Для реализации указанной нормы был принят ряд подзаконных правовых актов, определивших работу с неустойками в 2015 году. В текущем году данная норма по-прежнему остается актуальной, поскольку принят Федеральный закон № 390-Ф3, продливший рассматриваемую антикризисную меру еще на один год. 
DOI: $10.7256 / 1811-9018.2016 .11 .20823$

При цитировании этой статьи сноска на doi обязательна

Право и политика $11(203) \cdot 2016$

Предусмотренная Федеральным законом от 31.12.2014 № 498-Ф3 возможность осуществлять списание заказчиком уже начисленных сумм неустоек (штрафов, пеней) является одним из оснований освобождения поставщика (подрядчика, исполнителя) от гражданско-правовой ответственности. Эта мера призвана поддержать стабильное функционирование системы государственных за- купок. Исключением являются случаи, если в контракт включено условие о перечислении заказчиком сумм начисленных неустоек в соответствующий бюджет (для государственных (муниципальных) заказчиков) или о зачете неустойки при оплате контракта (для бюджетных, автономных учреждений, государственных унитарных предприятий), когда списание неустойки не производится.

\section{Библиография:}

1. Байкалов А.А. Право побеждает обязанность?!. К вопросу о невозможности списания неустойки.URL: https://pravorub. ru/articles/70994.html\#comments (дата обращения 10.10.2016).

2. Богданов Д.В. Понятие и юридическая природа освобождения от гражданско-правовой ответственности и ее исключения // Евразийский юридический журнал. 2012. № 1. С. 77-79.

3. Кузнецова О.А. Применение мер гражданско-правовой ответственности // Вестник Пермского университета. Юридические науки. 2012. № 4. С. 97-103.

4. Сергеева В.А., Маркитантова А.С. О списании неустоек по контрактам // Бюджет. 2016. № 3. С. 66-69.

5. Тихоненко И.Н.. Основания освобождения от юридической ответственности: Дис. ... канд. юрид. наук: 12.00.01. М., 1995. $129 \mathrm{c}$.

\section{References (transliterated):}

1. Baikalov A.A. Pravo pobezhdaet obyazannost'?!. K voprosu o nevozmozhnosti spisaniya neustoiki.URL: https://pravorub. ru/articles/70994.html\#comments (data obrashcheniya 10.10.2016).

2. Bogdanov D.V. Ponyatie i yuridicheskaya priroda osvobozhdeniya ot grazhdansko-pravovoi otvetstvennosti i ee isklyucheniya // Evraziiskii yuridicheskii zhurnal. 2012. № 1. S. 77-79.

3. Kuznetsova O.A. Primenenie mer grazhdansko-pravovoi otvetstvennosti // Vestnik Permskogo universiteta. Yuridicheskie nauki. 2012. № 4. S. 97-103.

4. Sergeeva V.A., Markitantova A.S. O spisanii neustoek po kontraktam // Byudzhet. 2016. № 3. S. 66-69.

5. Tikhonenko I.N.. Osnovaniya osvobozhdeniya ot yuridicheskoi otvetstvennosti: Dis. ... kand. yurid. nauk: 12.00.01. M., 1995. $129 \mathrm{~s}$. 